\title{
Multiple Myeloma-Associated Amyloidosis Mimicking Peritoneal Carcinomatosis: An Unusual Case Report
}

\section{Seyhun SUCU, (D) Zehra BOZDAĞ (1) Barış AĞAR (D) Hüseyin Çağlayan ÖZCANª, (D) Özge KÖMÜRCÜa, (D) Özcan BALAT ${ }^{\mathrm{a}}$ \\ Departments of \\ aObstetrics and Gynecology, \\ bPathology, \\ Gaziantep University Faculty of Medicine, Gaziantep, TURKEY}

Received: 19 Jun 2019

Received in revised form: 04 Jul 2019

Accepted: 04 Jul 2019

Available online: 05 Sep 2019

Correspondence:

Barış AĞAR

Gaziantep University Faculty of Medicine, Department of Obstetrics and Gynecology, Gaziantep,

TURKEY/TÜRKIYE

seyhunsucu@hotmail.com

\begin{abstract}
Amyloidosis is a disease caused by extracellular deposition of fibrous protein in various tissues and organs. It coexists with multiple myeloma in approximately $12 \%-15 \%$ of cases. Omental amyloidosis is rare. We report a 61-year-old woman with omental amyloidosis associated with multiple myeloma. She presented initial symptoms including abdominal ascites and pleural effusion. The patient was diagnosed as having peritoneal carcinomatosis with elevated CA125 level at the first evaluation. Exploratory laparotomy was performed and the histopathological examination revealed omental amyloidosis. Here we report an unusual case of multiple myeloma (MM)-associated omental amyloidosis with abdominal ascites and pleural effusion, which can be confused with peritoneal carcinomatosis. The possibility of amyloidosis in the differential diagnosis of abdominal ascites and pleural effusion should be considered.
\end{abstract}

Keywords: Amyloidosis; ascites; CA125 level, multiple myeloma

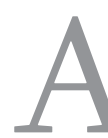

myloidosis, first reported in 1856, is a disease caused by extracellular deposition of fibrous protein in various tissues and organs. The disease mainly affects the kidneys, heart, and gastrointestinal tract. However, omentum and peritoneum are rarely affected. Amyloidosis develops in approximately $12-15 \%$ of multiple myeloma (MM) patients. ${ }^{1}$ The fibrous protein is produced by the myeloma cells. ${ }^{1,2}$ Although MM-associated amyloidosis has complex clinical findings, the symptoms are vague, which may lead to the misdiagnosis and delayed diagnosis of the disease. A definitive diagnosis of amyloidosis requires positive amyloid tissue staining, proof of plasma cell disorder, and amyloid linked organ dysfunction. ${ }^{3}$ In the present study, a patient having omental mass and peritoneal thickness with abdominal ascites and elevated CA 125 levels, mimicking peritoneal carcinomatosis but later diagnosed as MM, is being reported.

\section{CASE REPORT}

A 61-year-old woman was admitted to the gynecologic oncology department of Gaziantep University with abdominal distention, dyspnea, and elevated Canser Antigen 125 (CA125) levels as well as a history of mild hypertrophic cardiomyopathy. Her computed tomography revealed diffuse omental thickening (caking), unilateral severe pleural effusion, and abdominal ascites (Figure 1). She had no other pelvic abnormalities. Due to severe dyspnea, pleural drainage catheter was inserted. Pleural fluid tested negative for tuberculosis and malign cells. Diagnostic paracentesis showed 


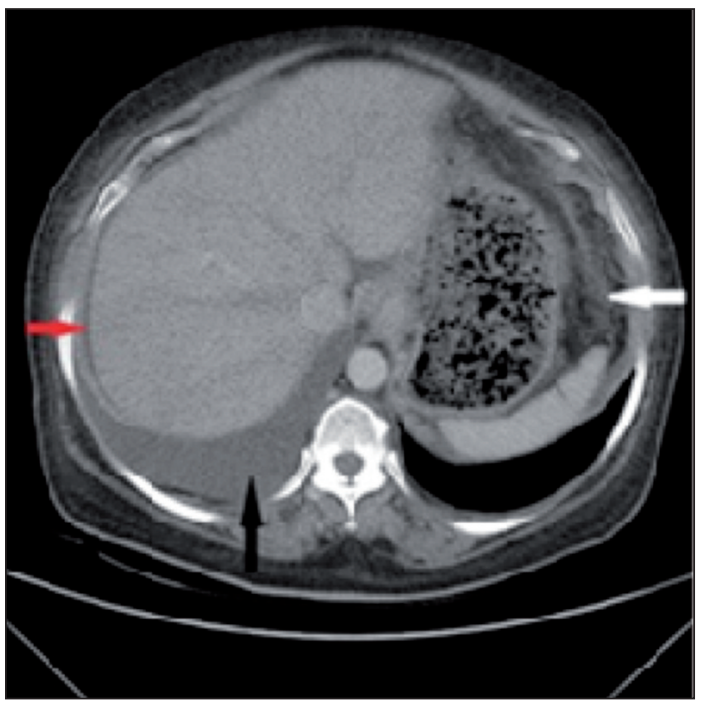

FIGURE 1: Axial upper abdominal CT without intravenous contrast medium demonstrating intraabdominal ascites (red arrow), pleural effusion at the right side of the lung (black arrow) and diffuse infiltrative omental mass (white arrow).

clear and yellow transudative fluid and reactive mesothelial cells in the ascites; however, there were no tumor cells. An elevated level of CA125 was found in control value $(447 \mathrm{U} / \mathrm{mL}$; normal $<35$ $\mathrm{U} / \mathrm{mL}$ ). CEA and CA19-9 levels were normal. All these preoperative findings were suggestive of peritoneal carcinomatosis. The patient underwent an exploratory laparotomy. Diffuse thickened peritoneum and omental cake with multiple solid-crispy fields were observed (Figure 2). Both ovaries, fallopian

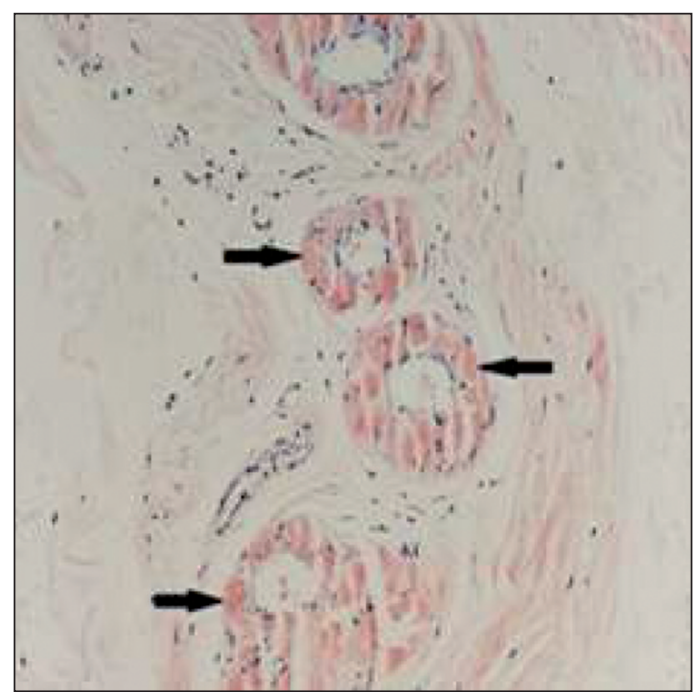

FIGURE 4: Positive staining of the amorphous material with Congo red, $\mathrm{x} 200$. tubes, and the uterus were normal in size and appearance with no solid or cystic mass at the adnexa of the uterus. A total omentectomy was performed and multiple peritoneal biopsies were taken. The biopsy samples evaluated by frozen section procedure were found to be benign. We aspirated approximately $2 \mathrm{~L}$ of ascites during the operation. Macroscopic examination of the omentum and peritoneum revealed nothing prominent. Hematoxylin and eosin staining showed amorphous, homogenous eosinophilic material around the adipose tissue and the vessel wall (Figure 3). The Congo red stain highlighted the amorphous material (Figure 4). Apple

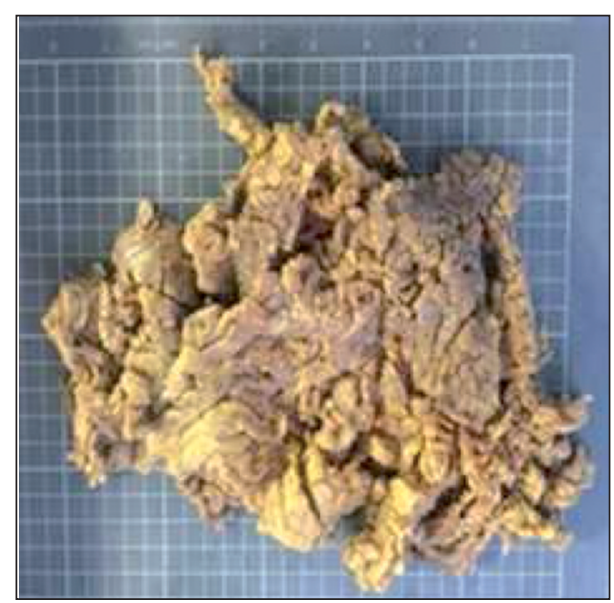

FIGURE 2: Macroscopic appearance of the omentectomy specimen.

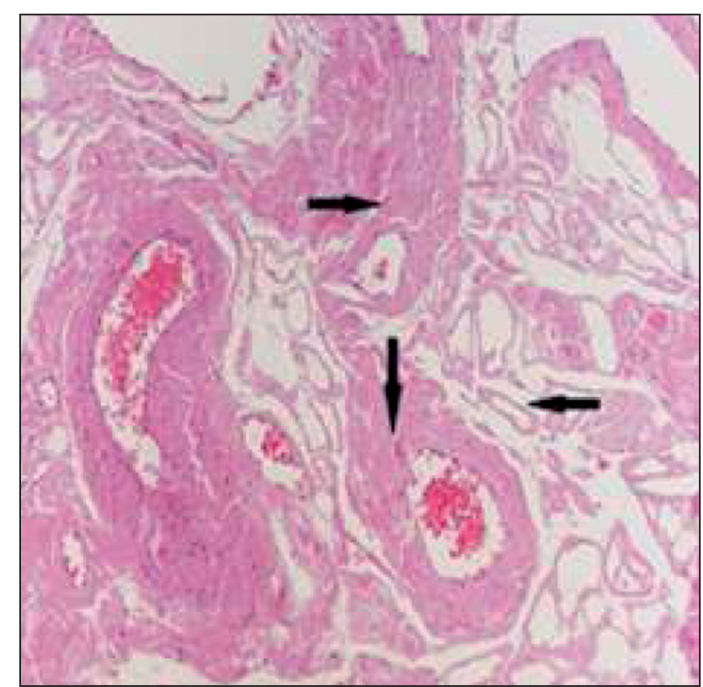

FIGURE 3: Amorphous and homogenous eosinophilic material accumulation around the vessel wall and adipose tissue, $\mathrm{HE}, \mathrm{x200}$. 
green birefringence was observed under polarized light. The immunohistochemical test confirmed this amyloid as primary type amyloid (AL). Bone marrow biopsy and bone marrow aspiration were performed and monoclonal plasma cell (Lambda positive) infiltrationwith MM was reported by the pathologist. Consequently, the patient was diagnosed with secondary omental and peritoneal amyloidosis due to MM. The patient was admitted to the medical oncology department of Gaziantep University for the treatment and follow-up. The VCD (bortezomib/cyclophosphamide/dexamethasone) treatment protocol was planned for the patient with her consent.

This study eas carried out eith the patient's approval.

\section{DISCUSSION}

Amyloidosis is a heterogeneous group of diseases caused by extracellular deposition of an insoluble protein in various organs and tissues. Amyloid is a protein that gets deposited in several organs and tissues including kidneys, heart, liver, lungs, and skin. It was first described by Wilksin in 1856. The three main types of amyloidosis are primary (AL), secondary (AA), and familial (ATTR) amyloidosis. All these types of amyloidosis differ in pathogenesis, clinical symptoms, and prognoses. Primary amyloidosis is associated with plasma cell dyscrasia and $30 \%$ of the cases are asymptomatic. ${ }^{1,4}$ Multiple Myeloma (MM) is the cause of approximately 20\% of amyloidosis. ${ }^{5}$ Unusual symptoms and findings may lead to misdiagnosis or delayed diagnosis. We report a patient with MM-associated primary amyloidosis whose initial symptoms were abdominal ascites and elevated CA125 level closely mimicking peritoneal carcinomatosis. The first case related to the peritoneal amyloid formation with ascites was reported in $1985 .{ }^{6}$ Very few cases that mimicked peritoneal carcinomatosis of omental amyloidosis have been reported. The final diagnosis is carried out pathologically with electron microscopy. ${ }^{4}$ Omental biopsy could be performed; however, in our case, explorative laparotomy was done due to a high suspicion of malignancy. Exploratory laparotomy revealed diffuse infiltration of the omentum related with transudative ascitic fluid. Ascites with primary amyloidosis may result from nephrotic syndrome, congestive heart failure, or hepatocellular disease. However, our patient demonstrated normal renal and liver function with mild hypertrophic cardiomyopathy. The ascites is a consequence of omental amyloid infiltration. The mesothelial cells increase level of CA125.

Amyloid depositions can mimic both neoplastic and nonneoplastic conditions. Therefore, omental amyloidosis should be considered as a possible reason for omental mass with abdominal ascites, pleural effusion, and elevated CA125 level. Primary amyloidosis can be idiopathic or associated with MM. Thus, screening tests, differential diagnosis, and evaluation of the primary disease in detail are necessary before the treatment.

\section{Source of Finance}

During this study, no financial or spiritual support was received neither from any pharmaceutical company that has a direct connection with the research subject, nor from a company that provides or produces medical instruments and materials which may negatively affect the evaluation process of this study.

\section{Conflict of Interest}

No conflicts of interest between the authors and / or family members of the scientific and medical committee members or members of the potential conflicts of interest, counseling, expertise, working conditions, share holding and similar situations in any firm.

\section{Authorship Contributions}

Idea/Concept: Barış Ağar, Seyhun Sucu; Design: Barış Ağar; Control/Supervision: Seyhun Sucu; Data Collection and/or Processing: Barış Ağar; Analysis and/or Interpretation: Barış Ağar,Seyhun Sucu, Çağlayan Özcan, Özge Karuserci, Zehra Bozdağ; Literature Review: Barış A ğar, Seyhun Sucu, Çağlayan Özcan; Writing the Article: Barış A ğar, Seyhun Sucu; Critical Review: Barış Ağar, Seyhun Sucu; References and Fundings: Barış Ağar, Seyhun Sucu; Materials: Barış Ağar, Seyhun Sucu, Zehra Bozdă̆, Çağlayan Özcan, Özge Karuserci. 


\section{REFERENCES}

1. Dinner S, Witteles W, Witteles R, Lam A, Arai $S$, Lafayette $R$, et al. The prognostic value of diagnosing concurrent multiple myeloma in immunoglobulin light chain amyloidosis. $\mathrm{Br} \mathrm{J}$ Haematol. 2013;161(3):367-72. [Crossref] [PubMed]

2. Girnius S, Seldin DC, Skinner M, Finn KT, Quillen $\mathrm{K}$, Doros $\mathrm{G}$, et al. Short and long-term outcome of treatment with high-dose melphalan and stem cell transplantation for multiple myeloma-associated AL amyloidosis. Ann Hematol. 2010;89(6):57984. [Crossref] [PubMed]
3. Ohashi T, Kikuchi N, Yamamoto T. Unusual milia amyloidosis as initial signs of multiple myeloma-associated systemic amyloidosis. Int J Dermatol. 2013;52(8):981-2. [Crossref] [PubMed]

4. AkI MN, Kho RM, McCullough AE, Collins JM, Lund JT, Magtibay PM. Mesenteric and omental amyloidosis mimicking intraperitoneal carcinomatosis. Surgery. 2008;144(3):473-5. [Crossref] [PubMed]

5. Lee HJ, Chang SE, Lee MW, Choi JH, Moon KC. Systemic amyloidosis associated with multiple myeloma presenting as periorbital purpura. J Dermatol. 2008;35(6):371-2 . [Crossref] [PubMed]

6. Mallet H, Humbert P, Dupond JL, Des Floris JL. Amyloid deposition in serosal membranes. Arch Intern Med. 1985;145(12):2264. [Crossref] [PubMed]

7. Zeillemaker AM, Verbrugh HA, Hoynck van Papendrecht AA, Leguit P. CA 125 secretion by peritoneal mesothelial cells. J Clin Pathol. 1994;47(3):263-5. [Crossref] [PubMed] [PMC] 